\title{
A CONTRIBUIÇÃO DA SEQUÊNCIA DE ENSINO FEDATHI NO PROCESSO DE ENSINO APRENDIZAGEM EM FÍSICA
}

\author{
Thiago Arrais Soares* Francisco Augusto Silva Nobre ${ }^{\dagger}$ \\ Polo 31-MNPEF (PROFIS), Universidade regional do Cariri - URCA \\ Av. Leão Sampaio, 170, CEP 63040-000 Juazeiro do Norte - CE
}

\begin{abstract}
Resumo
Apresentamos aqui um trabalho desenvolvido no ambiente escolar com a intenção de propor uma postura docente de mais diálogo com os alunos, entendendo o discente como um sujeito ativo na construção do conhecimento. Desenvolvemos nosso trabalho fazendo intervenções em sala de aula aplicando a sequência de ensino FEDATHI, elaborada inicialmente para o ensino e pesquisa em matemática. Mostramos como essa sequência de ensino poderia ser aplicada em física e se tornar uma ferramenta importante para aplicação na resolução de problemas orquestrando as atividades dos alunos e, acreditamos, favorecendo uma aprendizagem significativa. Essa sequência metodológica foi aplicada na resolução de problemas em física envolvendo o conteúdo de movimento harmônico simples, e em todas as etapas das intervenções os conhecimentos prévios dos estudantes foram considerados $e$ foram objetos de discussões em grupo, pois nossa pesquisa foi desenvolvida na óptica Ausubeliana, nos fazendo perceber a importância de identificar a estrutura cognitiva dos discentes e ensinar com base no que foi descoberto, nos seus conhecimentos prévios, favorecendo uma aprendizagem significativa. Deste trabalho foi gerado também um tutorial impresso em forma de livreto e aplicativo para computador e celulares, contendo os dados das intervenções, resultados, análises, juntamente com a teoria dos temas abordados, tentando gerar um debate na classe docente, sobre a Sequência FEDATHI aplicada em física. Finalizando, concluímos que o interesse produzido no aluno pela aplicação da Sequência FEDATHI durante as aulas foi crescente e acreditamos que a aprendizagem significativa foi motivada nos alunos Com isso entendemos que validamos a aplicação da Sequência FEDATHI no ensino de física, em especial para o conteúdo aplicado na intervenção pedagógica.
\end{abstract}

Palavras-chave: Ensino de Física. Sequência Fedathi. Aprendizagem Significativa.

\footnotetext{
*E-mail: thiagoarraisoares@gmail.com

†Bolsista de Produtividade PBI-FUNCAP. E-mail: augusto.nobre@urca.br
} 


\begin{abstract}
We present here a work developed in the school environment with the intention of proposing a teaching position of more dialogue with the students, understanding the student as an active subject in the construction of knowledge. We developed our work by making classroom interventions applying the FEDATHI teaching sequence, initially developed for teaching and research in mathematics. We show how this teaching sequence could be applied in physics and become an important tool for application in problem solving by orchestrating student activities and, we believe, favoring meaningful learning. This methodological sequence was applied in solving problems in physics involving the content of Simple Harmonic Motion, and in all stages of the interventions the previous knowledge of the students were considered and were objects of group discussions, since our research was developed in the Ausubelian optics, Making us realize the importance of identifying the cognitive structure of the students and teaching based on what was discovered, in their previous knowledge, favoring a meaningful learning. From this work was also generated a printed tutorial in the form of a booklet and application for computer and cell phones, containing the data of the interventions, results, analyzes, together with the theory of the topics addressed, trying to generate a debate with the teaching community, about the FEDATHI Sequence applied In physics. Finishing, we conclude that the interest produced in the student by the application of the FEDATHI sequence during classes was increasing and we believe that meaningful learning was motivated in the students. With this we understand that we validate the application of the FEDATHI sequence in physics teaching, especially for applied content in pedagogical intervention.
\end{abstract}

Keywords: Physics Teaching. Fedathi sequence. Meaningful Learning.

\title{
1 INTRODUÇÃO
}

Preocupado com a aprendizagem dos nossos alunos, e defendendo que aulas sejam motivadoras para criar no discente o interesse pela disciplina de física, apresentamos um trabalho desenvolvido no ambiente escolar com a intenção de propor uma nova postura docente em sala, visando o aluno como um sujeito ativo na construção do conhecimento.

Desenvolvemos nosso trabalho fazendo intervenções em sala de aula aplicando a sequência de ensino FEDATHI $^{1}$, e esperamos mostra como essa sequência de ensino pode ser aplicada em física e se tornar uma ferramenta importante para aplicação na resolução de problemas orientando as atividades dos alunos e favorecendo uma aprendizagem significativa.

Essa sequência metodológica, inicialmente pensada para solução de problemas de matemática, foi aplicada na resolução de problemas em física envolvendo o conteúdo de movimento harmônico simples, e

\footnotetext{
${ }^{1}$ A Sequência FEDATHI constitui uma proposta metodológica desenvolvida pelo professor Hermínio Borges Neto matemático e pesquisador da área de educação matemática da Universidade Federal do Ceará - UFC.
} 
em todas as etapas da intervenção os conhecimentos prévios dos estudantes foram objetos de discussões em grupo, pois nossa pesquisa foi também desenvolvida com o olhar Ausubeliano, nos fazendo perceber a importância de identificar a estrutura cognitiva dos discentes e ensinar com base no que foi descoberto, nos seus conhecimentos prévios, favorecendo a uma aprendizagem significativa.

Utilizamos uma abordagem de pesquisa qualitativa sempre verificando a interação entre os conceitos trazidos pelos alunos com os conceitos que propomos transmitir para assim alcançarmos uma aprendizagem significativa.

Quando falamos dos conceitos que o aluno já sabe, não estamos falando exatamente de saber o conteúdo, mas sim, de uma estrutura cognitiva que facilite o armazenamento dos assuntos a serem aprendidos. David Ausubel grande estudioso da psicologia educacional se refere em uma premissa básica na sua teoria de aprendizagem (1968, p. iv).

Se tivesse que reduzir toda a psicologia da educação a um só princípio, diria o seguinte: $\mathrm{O}$ fator isolado mais importante que influencia a aprendizagem é aquilo que o aprendiz já sabe. Averigue isso e ensine-o de acordo.

Desenvolvemos nosso trabalho fundamentado na teoria da aprendizagem significativa de Ausubel, utilizando como instrumentos de coleta a observação direta o questionário e o diário de campo.

Já a Sequência FEDATHI, configura-se para nós como a abordagem principal, sendo utilizada para conduzir a mediação do professor na sua prática docente. Na resolução tradicional de exercícios a quantidade de aplicações de tarefas de repetições de resoluções de questões é priorizada em relação à qualidade de abordagem e análise minuciosa de certa questão. Trabalhamos com questões que propiciaram um pensamento reflexivo e um aprendizado com significado na vida do estudante.

A Sequência FEDATHI é composta por quatro etapas sequenciais e interdependentes, denominadas: Tomada de Posição, Maturação, Solução e Prova, sendo o processo de ensino iniciado e terminado pelo professor. Inicialmente o docente seleciona e apresenta o problema relacionado ao conhecimento a ser abordado e ao final após as discussões realizadas com os alunos formaliza o conhecimento para direcionar o alunado a solução deste.

O conteúdo abordado foi a cinemática do movimento harmônico simples, conteúdo tal, que os alunos mostram uma recusa inicial pelo fato das funções que descrevem o movimento serem harmônicas, tidas pelos estudantes como de difícil compreensão. Visando incentiva-los para o tema proposto, os estudantes participaram de forma ativa com a oportunidade de construir seus próprios questionamentos e soluções.

David Ausubel (2003, p. 131) aponta também uma preocupação com relação ao modelo exagerado de levar em consideração os testes por memorização no ensino, sugerindo estratégias para superação desta realidade.

[...] uma vasta experiência na realização de exames faz com que os estudantes se tornem adeptos da memorização, não só de proposições e de fórmulas chave, mas também de causas, exemplos, razões, explicações e formas de reconhecimento e de resolução de "problemas tipo". Pode evitar-se melhor o perigo da simulação memorizada da compreensão significativa através de colocação de questões e de problemas que possuam uma forma nova e desconhecida e exijam uma transformação máxima de conhecimentos existentes. 
Nosso trabalho foi desenvolvido em uma escola da rede privada da Cidade de Juazeiro do Norte, no Estado do Ceará, com uma turma de alunos que não conseguiram aprovação em física no segundo ano do ensino médio e optaram pela progressão parcial ${ }^{2}$, participando da dependência na disciplina. Os alunos deverão rever todos os conteúdos vistos no ano anterior, mas para garantir que a Sequência FEDATHI seja aplicada sobre um conteúdo que os alunos ainda não viram, abordaremos a cinemática do Movimento Harmônico Simples, que não pertencer ao currículo do programa de ensino dessa instituição no referido ano. A turma apresentava 12 (doze) alunos, e funcionava no contra turno ${ }^{3}$ das aulas regulares da escola. Cada aula tinha duração de 50 min (cinquenta minutos), uma vez por semana durante os meses de abril e maio de 2015.

Realizamos a aplicação de um questionário estruturado aberto de sondagem para diagnosticar os conceitos que os estudantes já possuíam. Sugerimos o tema a ser trabalhado pelos alunos e a sequência de procedimentos a serem seguidas. Levantamos perguntas estimuladoras, esclarecedoras e orientadoras, como também ao final, baseado nas discussões e questionamentos dos discentes, propomos uma intersecção entre os modelos apresentados pelos alunos e o modelo geral do conhecimento em jogo.

Aplicamos a Sequência FEDATHI, visando produzir o conhecimento esperado em cada aula e fortalecer um modelo que desestruture o ensino tradicional onde na maioria das vezes não estimula e também não almeja a participação dos alunos na construção da compreensão e resolução dos problemas propostos em sala de aula.

Um ponto que é necessário destacar é que no desenvolvimento desse trabalho, buscamos também a validação da Sequência FEDATHI aplicada ao ensino de física, e, após a execução desse projeto, acreditamos que conseguiremos gerar na classe docente uma reflexão acerca da aplicação desta sequência no ensino de física, no intuito de potencializar suas vantagens que aqui serão expostas.

\section{CONSIDERAÇÕES TEÓRICAS}

Apresentaremos a seguir algumas questões que consideramos importante. Uma é um comparativo entre sequência FEDATHI e a sequência de George Polya, na qual a FEDATHI se configura como ferramenta de um novo plano didático da prática docente, tendo em vista que nas últimas décadas o ensino de física e das disciplinas científico-tecnológicas passam por uma crise (FOUREZ, 2003), que se reflete no comportamento em sala de aula do professor. Já a de Polya sugere passos para os discentes na resolução de problemas.

O segundo ponto, é que verificamos também que na literatura não tem uma definição formal para sequências de ensino e que se confunde na maioria das vezes com sequência didática. Portanto abordaremos também aqui suas definições, objetivos e pontos de divergência.

Fazendo uma retrospectiva das sequências de ensino verificamos que a maioria delas foram propostas para o Ensino de Matemática e prevendo favorecer um caminho (algoritmo) ${ }^{4}$ de resolução de problemas.

\footnotetext{
${ }^{2}$ É o processo que permite aos alunos seguirem com os estudos mesmo tendo pendências em disciplinas do ano anterior ao que estejam cursando, desde que a unidade escolar possua o sistema de avaliação indicado.

${ }^{3}$ Horário oposto ao período escolar regular com atividades complementares.

${ }^{4}$ É uma sequência finita de instruções bem definidas e não ambíguas, cada uma das quais devendo ser executadas
} 
Mas para o professor é difícil fazer a distinção entre problema e exercício, pois motivado pelos processos seletivos existentes para o ingresso no ensino superior ele se torna um transmissor de conteúdo e apresenta de forma quase inquestionável o caminho a ser seguido pelo aluno para a solução da situação abordada com exercício, sem fornecer momentos de reflexões para os estudantes que poderiam buscar relacionar os conceitos que já existem na sua estrutura cognitiva com o exercício proposto buscando solucioná-lo. Por essas razões se faz necessário a elaboração e aplicação de metodologias que venham abordar a resolução de problemas em sala de aula e um processo que pavimente sua solução visando à melhoria na qualidade da aprendizagem, mostrando ao professor a verdadeira diferença entre exercício de aplicação de conteúdo estudado e situações problemas. As sequências de ensino se comportam como ferramenta importante na melhoria da qualidade de ensino visando o aperfeiçoamento do processo ensino-aprendizagem, como forma de orientação dos alunos na resolução de problemas de suas disciplinas seguindo certos algoritmos, mas que segundo Michael Otte (1991, p.285), traduz uma realidade objetiva do momento da aplicação sem explicações da essência do objeto em estudo.

Diametralmente oposto ao pensamento conceitual e a evidencia intuitiva, está o pensamento algorítmico. [...] O pensamento algorítmico não se objetiva na evidência, mas no sucesso, e ele não pode saber de antemão se será bem sucedido ou falhará. $\mathrm{O}$ conhecimento algorítmico é o conhecer sem a percepção. Os algoritmos são relacionados apenas funcionalmente à realidade objetiva; eles não explicam nada.

Tendo em vista a necessidade da parte conceitual e da percepção do objeto abordado no estudo, as sequências de ensino também são aplicadas por estudiosos, transformando o educando em parte ativa do processo educacional, resgatando seu conhecimento de mundo e norteando a postura do educador em sala de aula, fortalecendo assim a teoria Ausubeliana, pois o conhecimento trazido pelos estudantes adquirem novos significados, os deixando mais elaborados.

\section{SEQUÊNCIA FEDATHI E A SEQUÊNCIA DE POLYA}

Analisando as sequências de ensino desenvolvidas para matemática a partir de John Dewey (HUETE e BRAVO, 2006, p.159) em 1910 até os teóricos dos dias atuais, verificamos que as sequências de ensino podem ser usadas em sala de aula para reger o trabalho do docente e dos alunos, como podem ser usadas somente pelos estudantes nas tarefas de resolução de problemas longe dos domínios escolares, seguindo algoritmos para construção das respostas previstas e esperadas para uma determinada atividade.

George Polya, matemático Húngaro (POLYA, 1945, p.4), no seu livro A Arte de Resolver Problemas", propôs, a partir de sua vivência docente no ensino de matemática, uma heurística de quatro passos para direcionar os discentes na resolução de problemas, desde seu enunciado até sua solução. 1) Compreensão do Problema: momento de entender o problema a ser resolvido, 2) Elaboração de um Plano: Construir um plano para solucionar o problema, partindo da determinação da(s) incógnita(s), 3) Colocando o plano

mecânica ou eletronicamente em um intervalo de tempo finito e com uma quantidade de esforço finita. Disponível em $<$ https://pt.wikipedia.org/wiki/Algoritmo>. Acesso em: 11 nov. 2015. 
em ação: momento de execução do plano proposto e 4) Reflexão: revisando a solução encontrada, para valida-la e tentar aperfeiçoar o caminho seguido, para servir de norte para as próximas situações.

O Grupo FEDATHI ${ }^{5}$ formalizou em 1996 (BORGES NETO, 2013) uma sequência de ensino para o estudo e pesquisa no ensino de matemática denominada Sequência FEDATHI, a qual é composta por quatro etapas de realização sequenciais e interdependentes, assim denominadas: 1) Tomada de Posição, 2) Maturação, 3) Solução e 4) Prova.

A sequência de George Polya está voltada para o desenvolvimento de resolução de problemas pelos estudantes seguindo etapas para a solução de um determinado problema, configurando-se assim uma sequência de ensino que orienta o discente no seu processo ensino-aprendizagem, no ambiente escolar ou não. Já a Sequência FEDATHI governa o campo do comportamento do docente em sala de aula mediante uma atividade a ser aplicada para ajudá-lo a conduzir a mediação das produções que serão desenvolvidas pelos alunos. Mas um professor sempre ativo na iniciativa das atividades, iniciando e terminando todo processo, inclusive propondo a partir do exposto pelos estudantes, a solução mais oportuna para a situação em jogo ${ }^{6}$.

Verificamos, que mesmo as sequências de ensino citadas terem sido estabelecidas para aplicações distintas e em tempos diferentes, elas apresentam pontos de convergência.

A Professora Maria José de Araújo Sousa (Souza, 2010, p.52), buscando reconhecer os principais elementos e pontos em comum das Sequências de Ensino e modelos teóricos realizou um levantamento histórico desde Dewey - 1910, passando por George Polya - 1954, Michele Artigue - 1988, até a Sequência Fedathi - 1996. Com isso, foi capaz de apresentar os seguintes pontos de convergência das sequências relacionando-os com as quatro etapas da Sequência FEDATHI:

1. A COMPREENSÃO DO ENUNCIADO (Tomada de posição) Versão da linguagem verbal para a linguagem matemática;

2. A COMPREENSÃO DO PROBLEMA (Tomada de posição) Consciência das relações lógicas conceituais e matemáticas que intervêm;

\section{A BUSCA DE VÁRIAS ESTRATÉGIAS DE RESOLUÇÃO (Maturação);}

\section{A APLICAÇÃO DAS ESTRATÉGIAS (Solução);}

\section{A REVISÃO E A COMPROVAÇÃO DO PROCESSO SEGUIDO (Prova).}

Os pontos de convergência elencados no Quadro1, e relacionados com os passos da Sequência FEDATHI, nos mostra que essa sequência de ensino, como metodologia da atuação do professor em sala de aula, pode ser aplicada em diversas áreas do conhecimento, como faremos no desenvolvimento desse trabalho no Ensino de Física.

\footnotetext{
${ }^{5}$ Grupo de Pesquisa em Educação Matemática, atualmente composto por professores da Universidade Federal do Ceará - UFC, Universidade Estadual do Ceará - UECE e alunos do curso de Mestrado e Doutorado da Faculdade de Educação FACED - UFC.

${ }^{6}$ Definição de grandezas, solução de problemas, construção de gráficos, etc.
} 
O papel do professor em sala de aula é muito debatido hoje pelos estudiosos que acreditam que a educação vai além do ambiente escolar e que na própria escola os meios de informação disponíveis, como jornais, revistas, internet, etc. podem ser usados pelos discentes para aprenderem a buscar seu próprio conhecimento, como afirma Libâneo (2003, p. 26)

[...] a escola precisa deixar de ser meramente uma agência transmissora de informação e transformar-se num lugar de análises críticas e produção da informação, onde o conhecimento possibilita a atribuição de significados à informação. Nessa escola, os alunos aprendem a buscar a informação (nas aulas, no livro didático, na TV, no rádio, no jornal, nos vídeos, no computador etc.), e os elementos cognitivos para analisá-la criticamente e darem a ela um significado pessoal.

Tendo em vista esta situação, a Sequência FEDATHI, sequência aplicada na interverção em sala de aula desse trabalho, proporciona na sua proposta o que Assmann defende como postura do docente em sala de aula: que a "função já não será o da transmissão de saberes supostamente prontos, mas o de mentores e instigadores ativos de uma nova dinâmica de pesquisa-aprendizagem. ” (ASSMANN, 2000, p. 08)

\section{SEQUÊNCIA DE ENSINO E SEQUÊNCIA DIDÁTICA}

No capítulo de livro, Sequências no Ensino da matemática: Retrospectiva histórica de Dewey a Fedathi; no livro Sequência Fedathi, Souza (2013, p.50), sugere que as Sequências de Ensino são empregadas em um contexto de organização de um determinado saber, em etapas sequenciais, como forma de produzir um conhecimento específico.

Os termos Sequência de Ensino e Sequência Didática a priori podem sugerir significados idênticos, mas em trabalhos publicados e propostas de pesquisadores e professores que escrevem sobre metodologia para ajudar a desenvolver etapas na construção do conhecimento, essas denominações sofrem variações. Artigue (1996 apud PAIS, 2001, p.157) define de forma satisfatória Sequência didática, para concretizarmos realmente a diferença entre essas designações.

Sequência Didática é um conjunto de aulas planejadas e analisadas previamente com a finalidade de observar situações de aprendizagem, envolvendo os conceitos previstos na pesquisa didática [...] tal como acontece na execução de todo projeto, é preciso estar atento durante as sessões ao maior número de informações que podem contribuir no desenvolvimento do fenômeno investigado.

A professora Maria José (SOUZA, 2013, p.50), apresenta um quadro ${ }^{7}$ comparativo (Tabela 1), para definições e objetivos entre sequências didáticas e sequências de ensino. Sua preocupação em buscar as definições para as sequências apresentadas se deu para tentar facilitar o entendimento das propostas fundamentadas nas sequências de ensino.

\footnotetext{
${ }^{7}$ Quadro modificado do original produzido por (SOUZA, M. J. de A., 2013, p.50), retirando a definição e objetivos de situação didática, que não será abordado nesse trabalho.
} 
Revista do Professor de Física • Brasília, vol. 1, n. 2 • 2017

Tabela 1: Quadro comparativo de conceitos e objetivos acerca de sequência de ensino e sequência didática.

\begin{tabular}{l|c|c}
\hline \hline & SEQUÊNCIA DIDÁTICA & SEQUÊNCIA DE ENSINO \\
\hline \hline \multirow{2}{*}{ DEFINIÇÃO } & $\begin{array}{c}\text { Refere-se à organização de uma } \\
\text { sequência de aulas, geralmente } \\
\text { planejadas para pesquisas } \\
\text { relacionadas à Didática, podendo } \\
\text { ser também uma produção para o } \\
\text { próprio ensino. }\end{array}$ & $\begin{array}{c}\text { Refere-se à organização de um } \\
\text { determinado saber, em etapas } \\
\text { sequenciais, como forma de } \\
\text { produzir um conhecimento } \\
\text { específico. }\end{array}$ \\
\hline \multirow{2}{*}{ OBJETIVOS } & $\begin{array}{c}\text { Desenvolver pesquisas; } \\
\text { Ções voltadas para o ensino }\end{array}$ & $\begin{array}{c}\text { Organizar em etapas sequenci- } \\
\text { ais, produções específicas de } \\
\text { ensino }\end{array}$ \\
\hline
\end{tabular}

Entender a diferença entre os conceitos descritos acima, nos fundamenta e facilita a compreensão da aplicação da Sequência FEDATHI na Física, como etapas metodológicas a serem seguidas em encontros ou aulas, para orientar o comportamento do docente na regência dos seus alunos, em busca da construção do conhecimento sempre buscando um aprender significativo.

As sequências de ensino podem ser aplicadas nas mais diversas formas do conhecimento, na área de humanas, da natureza, linguagens, saúde, como também as sequências didáticas, sendo esta muito utilizada por estudiosos da didática da matemática francesa e Engenharia Didática ${ }^{8}$.

Apesar de possuírem definições distintas, possuem relações. A Sequência Didática pode organizar uma sequência de aulas planejadas para aplicar as Sequências de Ensino, como etapas sequenciais para produzir conhecimento, abordando seu objetivo de organizar e orientar produções no ensino. Por exemplo, no presente trabalho envolvendo o conteúdo de movimento harmônico simples, desenvolvemos uma Sequência Didática para estruturar o número de aulas necessárias e quais tópicos seriam abordados em cada uma com seus respectivos objetivos, e a Sequência de Ensino nos orientou durante a realização de cada aula, sendo instrumento de orientação de como abordar o assunto, que perguntas fazer aos estudantes e qual avaliação final realizar.

\section{A SEQUÊNCIA FEDATHI NA FÍSICA}

A Sequência de Ensino FEDATHI, de acordo com Minayo (2007, p. 44), se configura como uma metodologia a fim promover ferramentas que direcione o comportamento dos docentes em sala de aula e transformar o aluno em seu processo de aprendizagem num sujeito ativo, construindo seus próprios conhecimentos.

\footnotetext{
${ }^{8}$ A Engenharia Didática, vista como metodologia de pesquisa, se caracteriza em primeiro lugar por um esquema experimental baseado em "realizações didáticas" em sala de aula, isto é, sobre a concepção, a realização, a observação e análise de sequências de ensino. (ARTIGUE, 1996 apud PAIS, 2001, p.104).
} 
Buscamos a resposta da aplicabilidade da Sequência FEDATHI na resolução de problemas de física. Desenvolvemos nosso projeto também como uma pesquisa-ação, na qual o cooperativismo entre os envolvidos torna a intervenção diferenciada do ensino tradicional e o profissional da educação tenta melhorar sua prática. THIOLLENT (2000, p.14) define a pesquisa-ação como sendo:

[...]um tipo de pesquisa social com base empírica que é concebida e realizada em estreita associação com uma ação ou com a resolução de um problema coletivo e no qual os pesquisadores e os participantes representativos da situação ou do problema estão envolvidos de modo cooperativo ou participativo.

A aplicação do nosso trabalho apresentou como objetivo geral, estudar o efeito da atividade de situações problema em física aplicando a Sequência FEDATHI, fundamentado também na teoria da aprendizagem significativa de David Ausubel, tornando os estudantes mais ativos em seu processo de aprendizagem, e teve os seguintes objetivos específicos:

(a) Propor modelos de análise qualitativa de situações problema.

(b) Favorecer aos discentes a ampliação do conhecimento pelas interações com o grupo e o professor, e sempre propiciando sua participação durante todo o processo.

(c) Compreender analítica e geometricamente a cinemática do Movimento Harmônico Simples.

Durante a intervenção pedagógica, todas as fases da Sequência FEDATHI foram aplicadas como indica essa sequência de ensino, sempre dialogando com a Teoria da Aprendizagem significativa, tentando fazer a ligação das ideias e conceitos já existentes no aluno com o novo conhecimento, para ao final do processo de aprendizagem esse novo saber fazer parte de sua estrutura cognitiva.

1. Tomada de Posição: Momento no qual o professor expõe o problema para o estudante, partindo de um cenário particular com o objetivo de propor um modelo genérico ao final. Nessa etapa o docente pode aproveitar colocações dos alunos para iniciar a apresentação da situação problema, assim fortalecerá a relação da Sequência FEDATHI e a Teoria da Aprendizagem Significativa de Ausubel.

2. Maturação: Período de discussão entre o professor e os alunos, onde os discentes buscam identificar a direção pertinente para a solução da situação proposta na etapa anterior.

3. Solução: Fase na qual os estudantes organizam suas produções e apresentam modelos para a solução do problema proposto. Os modelos podem ser desenhos, esquemas, fórmulas, explanados de verbalmente ou escritos.

4. Prova: É o momento onde o professor após discussões sobre as soluções apresentadas, expõe o modelo científico a ser aprendido pelo aluno, que o levará a solução do problema, sempre mantendo relação com as formulações desenvolvidas pelos discentes. 


\section{A NATUREZA DA PESQUISA}

Inicialmente investigamos junto a um grupo de alunos suas dificuldades em relação a cinemática do movimento harmônico simples, que envolve as funções trigonométricas seno e cosseno, para a seguir aplicarmos a Sequência FEDATHI como orientação da postura do professor em sala de aula.

A pesquisa foi realizada no perímetro de natureza qualitativa ${ }^{9}$ com o professor como próprio pesquisador, tendo ainda características de pesquisa-ação. Mas os dados obtidos ora eram definições de grandezas, determinação de funções, ora eram valores numéricos calculados a partir das funções encontradas. Logo, a pesquisa com caráter principal qualitativo, não deixa de ter suas interpretações quantitativas.

Para Erickson (op. cit., p. 121), a pesquisa interpretativa envolve: a) intensa e ampla participação no contexto pesquisado, b) cuidadosos registros do que ocorre nesse contexto juntamente com outras fontes de evidência (e.g., anotações, documentos, exemplos de coisas feitas pelos sujeitos, gravações em áudio ou em vídeo) e c) análise reflexiva de todos esses registros e evidências assim como descrição detalhada (i.e., utilizando a narrativa e transcrições literais de verbalizações dos sujeitos).

O professor na qualidade de orquestrador da pesquisa e sujeito ativo no processo durante todo seu desenvolvimento, sendo observador e participante das situações propostas, inova sua prática docente com a aplicação em sala de aula de novas metodologias de ensino, favorecendo uma melhora na aprendizagem dos alunos e na sua atividade laboral educacional, o tornando um pesquisador absorto na situação de interesse.

\section{O PROCESSO DE INTERVENÇÃO}

A aplicação da Sequência FEDATHI foi realizada em 06 aulas, na turma do segundo ano do ensino médio de um colégio da rede privada de ensino da cidade de Juazeiro do Norte - CE. A turma era composta de 12 (doze) alunos que não obtiveram aprovação no ano anterior e optaram cursar o terceiro ano do ensino médio realizando progressão parcial ${ }^{10}$ na disciplina de física. Essa turma foi escolhida de forma proposital, pois tínhamos alunos que poderiam apresentar conhecimentos prévios importantes para o desenvolvimento desse trabalho, como também iriam ser apresentados ao estudo de um conteúdo que no ano anterior não estudaram.

As aulas foram realizadas nos meses de maio e junho do ano de 2015 no turno vespertino, como duração de 50 minutos cada, com 1 (um) encontro semanal, com autorização da direção da escola e com a ciência de que os encontros eram parte de uma pesquisa de mestrado, mas que durante todo seu desenvolvimento os alunos estariam sendo avaliados, pois era importante para escola a quantificação da aprendizagem.

\footnotetext{
${ }^{9}$ Erickson (1986, p. 119), prefere o termo pesquisa interpretativa para se referir a toda uma família de abordagens de pesquisa participativa observacional, em lugar de pesquisa qualitativa [...].

${ }^{10}$ É o estudo continuado de uma disciplina do ano anterior, na qual o aluno foi reprovado, porém avançou de ano.
} 
Na primeira aula do ano letivo que ocorreu no dia dez do mês de fevereiro, os alunos foram apresentados a ementa do curso de progressão parcial em física, na qual constava que nos meses de maio e junho o estudo seria sobre a cinemática e dinâmica do movimento harmônico simples (MHS). Aproveitamos esse momento, para aplicar um questionário estruturado com questões abertas e fechadas, com a intenção de identificar as concepções dos alunos acerca dos conteúdos e podermos produzir a pavimentação da nossa investigação. E do mês de fevereiro até a metade do mês de maio, antes da aplicação da Sequência FEDATHI, os alunos estudaram de maneira tradicional ${ }^{11}$ os conteúdos da disciplina.

No primeiro encontro no mês de maio, para iniciar a aplicação da Sequência FEDATHI, realizamos uma sondagem com os alunos a respeito dos conhecimentos prévios sobre as funções harmônicas e algumas definições pertinentes ao estudo em questão, para sabermos a que nível de abordagem do conteúdo que deveríamos começar a realização da nossa intervenção pedagógica. Souza (2013, p.15) no livro sequência FEDATHI - Uma proposta Pedagógica para o Ensino de Ciências e Matemática mostra a importância do diagnóstico.

[...] o diagnóstico pode ser realizado por meio de dois momentos, o primeiro em que o professor define quais conhecimentos prévios os alunos deveriam ter para a apreensão do novo conhecimento, e o segundo, a realização da investigação junto aos alunos a fim de averiguar se os estudantes são detentores destes conceitos.

A escola onde realizamos a intervenção pedagógica, só oferece uma aula semanal de 50 minutos para progressão parcial, mas em acordo com a coordenação do colégio e com o consentimento dos alunos, realizamos neste primeiro encontro, duas aulas de 50 minutos cada, com um intervalo de 25 minutos, entre uma aula e outra. Na primeira aula foi aplicado o objeto de sondagem com os discentes, e durante o intervalo fizemos um apanhado dos tópicos que os estudantes apresentaram nesta sondagem. No segundo momento houve aula expositiva envolvendo os pontos elencados pelo docente que apresentavam algum déficit de conhecimento.

Durante as aulas desta intervenção os alunos foram apresentados ao tema através de explanação do professor no quadro e/ou com simulações através do uso do computador. Em todos os encontros foram formados grupos de quatro alunos para o desenvolvimento do trabalho, totalizando três grupos. Ao final de cada aula após a conclusão do proposto pelo docente, os alunos juntamente com o professor se reuniam para debaterem os resultados alcançados, com o objetivo de promover uma intersecção geral dos conteúdos abordados.

O professor nessa prática foi o personagem mediador da situação, mas sempre iniciando o processo e concluindo, sugerindo o tema abordado na aula e propondo ao final das análises dos modelos propostos pelos alunos, o modelo geral de solução. O primeiro encontro da aplicação da Sequência FEDATHI, foi iniciado com a explanação a respeito dos movimentos oscilatórios. Foram apresentados aos alunos de forma oral e com imagens no quadro usando o projeto multimídia, exemplos de oscilações ${ }^{12}$, de forma a

\footnotetext{
${ }^{11}$ Ensino pautado no método de transmissão de informações, via oral, na sala de aula sem intercambio externo ou experimentação ativa, onde o aluno é visto como depositário e alvo de informações e o professor cumpre o papel de transmissor do conhecimento.

${ }^{12}$ Relógio de Pêndulo, movimento de um trapezista de circo, vibração de uma corda de violão, pistões nos motores dos carros, balanço de um parque de diversão, movimento das assas de um beija-flor, diafragmas nos alto-falantes, etc.
} 
não usar os nomes usuais para amplitude e oscilação completa na explanação, usando alguns sinônimos.

Foi sugerido aos discentes que fossem formados três grupos de quatro alunos, para solucionarem a situação-problema apresentada (Tomada de Posição), que consistia em definir o MHS, a amplitude e determinar quando uma oscilação completa se processava no movimento. Ressaltamos também que os estudantes poderiam questionar, colocar suas dúvidas e fazer argumentações ao professor.

Os alunos reunidos nos seus grupos com a limitação de não compartilhar ideias com os demais da outra equipe, desenvolviam seus caminhos a fim de determinar seus modelos (Maturação). Durante essa etapa os alunos fizeram apenas um questionamento. A aluna L.B. perguntou "se o corpo conclui uma oscilação completa quando volta para o mesmo lugar que saiu?". Tentando apenas estimular a reflexão, propomos a recordação das condições iniciais dos movimentos em geral.

Após vinte minutos, todos a partir de seus lugares na sala explanaram suas definições sobre as grandezas solicitadas que foram discutidas com todos os estudantes e demais colegas de forma a chegar às definições desejadas (Solução).

Finalizamos a aplicação da Sequência FEDATHI com a (Prova), que consistiu na apresentação mais abrangente do modelo geral das definições solicitadas e que podem ser aplicadas no movimento harmônico simples, ou em qualquer outra situação que se necessite do entendimento envolvido para determinar os conceitos produzidos.

Percebemos que as produções dos alunos não apresentavam divergências exageradas entre si, nem da solução desejada, mas necessitavam de uma formalização técnica, elaborada pelo professor.

Iniciamos o segundo encontro apresentando a simulação de um pêndulo simples oscilando, com possibilidade de modificação na amplitude do movimento, para verificação de sua dependência com as grandezas objeto de definição dessa aula (Tomada de Posição) e foi solicitado aos alunos apresentar as definições de Período e Frequência do MHS.

Usamos a simulação do Laboratório de Pêndulos do Phet Interactive Simulations, da University of Colorado, disponível em https://phet.colorado.edu/pt_BR/simulation/pendulum-lab. A simulação foi usada como ferramenta didática para facilitar a visualização dos discente em relação ao movimento estudado. Segundo Medeiros as simulações são

[...]representações ou modelagens de objetos específicos reais ou imaginários, de sistemas ou fenômenos, elas englobam uma vasta classe de tecnologias, do vídeo à realidade virtual, para sua elaboração é necessário um modelo de uma situação real, modelo este matematizado e processado pelo computador. (MEDEIROS, A.; MEDEIROS, C., 2002, p. 79)

Novamente os alunos foram reunidos em grupos para desenvolverem seus caminhos a fim de determinar seus modelos (Maturação). Durante essa etapa os alunos não fizeram nenhum questionamento, mas, indagamos se a frequência poderia ser obtida em dias ou semanas. E após quinze minutos, todos a partir de seus lugares na sala explanaram suas definições sobre as grandezas solicitadas que foram discutidas pelo professor com todos os estudantes e demais colegas de forma a chegar as definições desejadas (Solução).

Finalizamos a aplicação da sequência Fedathi com a (Prova), que consistiu na apresentação mais abrangente do modelo geral das definições solicitadas e que podem ser aplicadas no movimento harmônico simples, ou em qualquer outra situação que se necessite do entendimento envolvido para determinar os conceitos produzidos. 
Percebemos que nessa aula o intervalo de tempo de reflexão sobre os modelos que seriam apresentados foi menor, os alunos estavam mais participativos e inseridos no modelo de condução da aula, proposta.

Já o terceiro encontro teve o objetivo de relacionar o movimento harmônico simples com o movimento circular uniforme. Começamos a intervenção indagando aos alunos se os mesmos conseguiriam identificar uma relação entre o MHS e o movimento circular uniforme, (Tomada de Posição).

Os alunos se reuniram novamente em grupo, mas agora em duas equipes de seis discentes. Iniciaram a construção da proposta de modelos (Maturação). Os dois grupos questionaram após alguns minutos de reflexão sobre a situação-problema abordada: “como um movimento retilíneo o MHS poderia se relacionar com um movimento circular?"

Depois de alguns minutos os grupos quase que simultaneamente, falaram que o movimento retilíneo apresentado no quadro era um movimento oscilatório, restava saber se um MHS (Solução). Então depois das discussões entre os dois grupos e o professor, foi apresentado (Prova), que a sombra do corpo em MCU projetada realizava um MHS.

No quarto encontro tínhamos o objetivo de determinar a função horária da elongação do MHS. Inicialmente solicitamos aos alunos que verificassem individualmente nas suas anotações e relembrassem da relação do MHS e MCU. Depois da formação de três grupos de quatro discentes, o professor propôs (Tomada de Posição) que os alunos determinassem uma função horária para calcular as posições do objeto oscilante em MHS.

Os estudantes mais uma vez debatendo entre si nos seus respectivos grupos tentavam desenvolver um modelo que possibilitasse o cálculo da elongação do corpo em MHS (Maturação). Vários questionamentos foram levantados, mas a equipe composta por L.B., M.G., G.O., e A.B.T., fez um questionamento com a seguinte pergunta: "Vamos usar esse ângulo da figura para alguma coisa?", e mais uma vez mediando a situação, tentamos estimular a produção com a explanação das razões trigonométricas.

Após dez minutos, ainda de discussões em grupos isolados, apenas duas equipes apresentaram um modelo a partir do cálculo do cosseno do ângulo (Solução). A solução da aluna G.O. está representa na Figura 1.

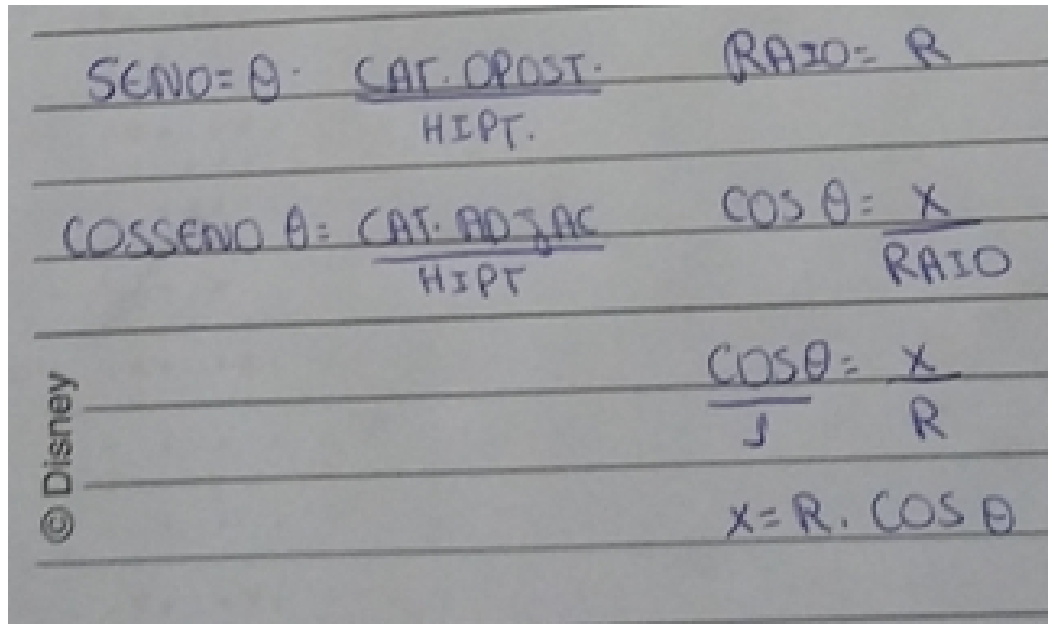

Figura 1: Modelo de função horária da elongação proposto pela aluna G.O. 
Passando agora para o sexto e último encontro da série de aplicação da Sequência FEDATHI, tivemos como objetivo neste, a construção do gráfico cartesiano da posição versus tempo do MHS. Foi apresentado inicialmente a simulação de um oscilador massa-mola disponível em http://slideplayer.com.br/slide/8842462, que apresentava a formação de dois gráficos provenientes do movimento oscilatório do bloco, com o intuito do aluno perceber como os gráficos se apresentavam.

Logo após a formação dos três grupos de quatro alunos, foi proposto aos discentes que construíssem o gráfico que relacionasse a elongação variando com o tempo no sistema cartesiano (Tomada de Posição). Novamente na etapa de (Maturação), os estudantes reunidos nos seus grupos debateram entre si, tentando desenvolver um modelo que possibilitasse construir o gráfico proposto e levantaram alguns questionamentos, como a dúvida de saber se o gráfico poderia ser retas e se o gráfico de um aluno poderia ser diferente do outro, etc.

$\mathrm{Na}$ intenção de orientar os alunos pedimos que eles analisassem a função horária das elongações, pois ela determinava o gráfico solicitado. E depois de algum tempo os alunos apresentaram seus modelos, debatendo-os com o professor (Solução). Um gráfico produzido pela aluna A.B.T. está representado na Figura 2.

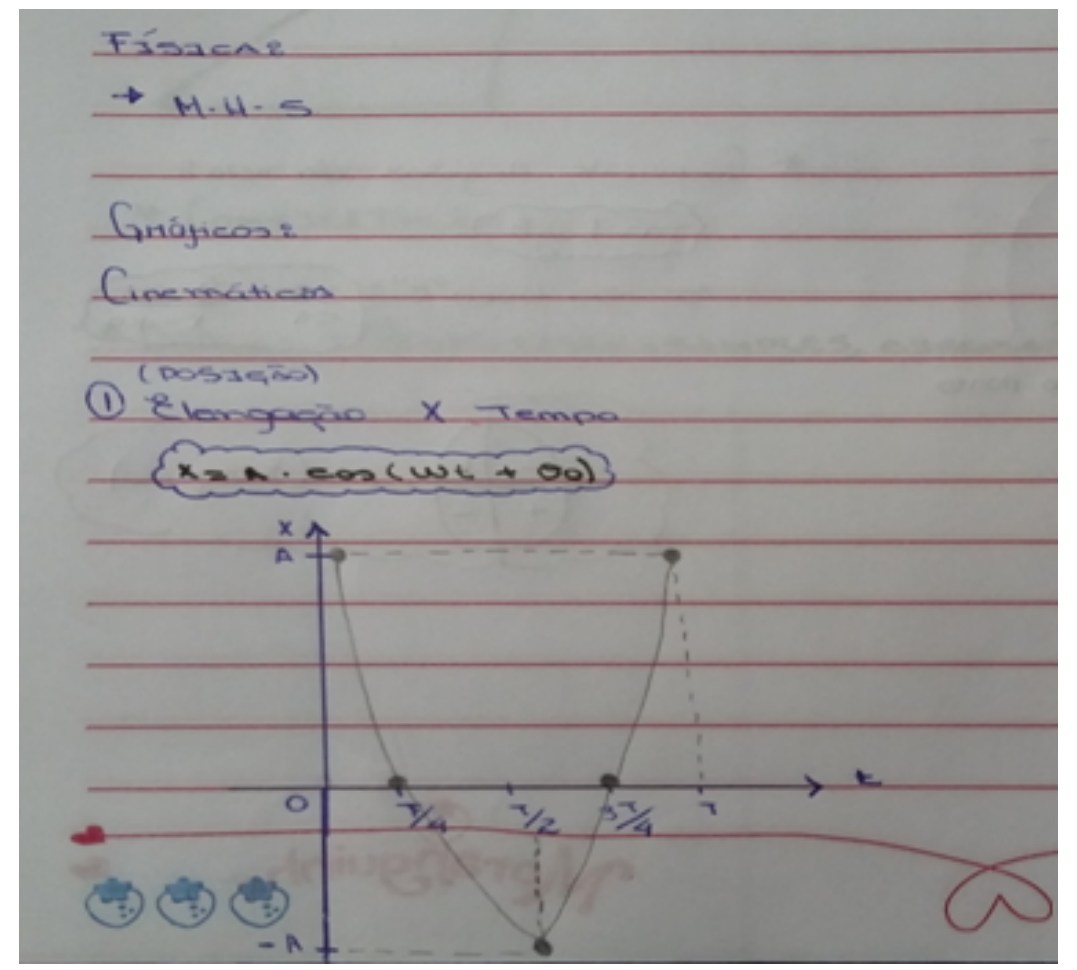

Figura 2: Modelo de função horária da elongação proposto pela aluna G.O.

A aula foi finalizada com a apresentação formal do modelo geral (Prova), tentando produzir uma aprendizagem significativa, com a incorporação do gráfico de maneira a alcançar uma hierarquia privilegiada na sua estrutura cognitiva.

$\mathrm{Na}$ construção dos gráficos podemos observar dois modelos produzidos. Um modelo de forma qualitativa como representado na Figura 2 e outro quantitativo, onde um aluno atribuiu valores para um 
determinado exemplo proposto por ele mesmo determinando um modelo de solução viável.

\section{CONCLUSÃO}

Nas aulas com a aplicação da Sequência FEDATHI, verificamos que todas as etapas foram aplicadas e de maneira sequencial, com a etapa de maior duração de tempo sendo a Maturação. Durante a execução dessa etapa do processo percebemos que em algumas situações os alunos necessitariam de mais tempo para amadurecimento dos modelos que seriam propostos, mas pelo tempo da aula se esgotando, preferimos aproveitar os modelos já estabelecidos com mesmo e propor o modelo geral na etapa da Prova, mas esclarecendo as dúvidas ainda existentes dos alunos, para favorecer uma ancoragem com significado edificador nas suas estruturas cognitivas, tentando alcançar uma aprendizagem significativa.

Verificamos que nas aulas que eram apresentadas algumas simulações computacionais de modelos físicos, os alunos mostraram mais interesse em entender os conceitos físicos envolvidos no movimento, além daqueles propostos pelo professor. A apresentação de imagens projetadas no quadro através do computador, também foi uma ferramenta que se configurou em uma forma de estimular os alunos, na etapa de Tomada de Posição da Sequência FEDATHI.

Ao final da quarta aula os alunos perguntaram se não iriamos trabalhar com gráficos. Diante dessa sugestão e baseado no que preconiza a Sequência FEDATHI, que o aluno pode ser o iniciador da proposta da situação-problema na aula, apresentarmos a construção gráfica da elongação do MHS. Percebemos que com a aceitação por parte do professor da sugestão dos alunos, os mesmos mostraram mais interesse e motivação para produzir seus modelos.

A Sequência FEDATHI apresenta como objetivos, segundo Souza (2013, p.40): Apresentar um modelo de ensino, que inclua a investigação científica como uma das etapas na elaboração do conhecimento; oferecendo elementos que contribuam para as ações e intervenções do professor no processo de ensino e propiciar a participação ativa do aluno durante todo o processo de ensino. Entendemos que os objetivos foram alcançados de forma clara e evidente.

Verificamos nos alunos durante a aplicação da sequência em cada aula, participação, interação, questionamentos, debates e a incorporação de um novo saber. Acreditamos ter sido um mediador com características de planejamento, estimulação, esclarecimentos e avaliação sem muita interferência nos modelos propostos pelos discentes.

Esperamos que a aprendizagem dos alunos tenha sido significativa, pois não é fácil definir se houve ou não aquisição significativa. Desenvolvemos nossas aulas de forma a sempre levar em consideração os conhecimentos prévios dos alunos e tentando incorporar o objeto de estudo de forma a obter uma hierarquização importante na estrutura cognitiva dos mesmos.

A pesquisa nos mostra que a Sequência FEDATHI foi muito bem aplicada ao ensino de física, podendo ser caracterizada como ferramenta metodológica importante no estudo de conteúdos físicos em sala de aula, transformando o aluno em pesquisador de seus próprios modelos de solução e regendo o comportamento do professor.

Num primeiro trabalho, realizado em 2013, que visou a aplicação da Sequência FEDATHI ao ensino de Física, apresentado no livro Sequência Fedathi (Borges coord. 2013) no capítulo, Uma Experiência 
de Aplicação da Sequência Fedathi no Ensino de Física (Nobre coord. 2013, p 119), observou-se a necessidade de uma pequena adaptação da mesma. Porém, no trabalho apresentado aqui, esta sequência de ensino foi perfeitamente aplicada em todas suas etapas. A principal razão, acreditamos ser devido ao fato de termos trabalhado com questões, que além da discussão teórica, havia uma necessidade de solução matemática.

Mostramos com esse trabalho, que o interesse produzido no aluno pela aplicação da Sequência FEDATHI durante as aulas foi crescente e sugere a nós professores uma reflexão de mudança de comportamento dentro da sala de aula.

Finalmente acreditamos que a aprendizagem significativa foi motivada nos alunos e que a Sequência FEDATHI foi a ferramenta utilizada para tal fim. Com isso entendemos que validamos a aplicação da Sequência FEDATHI no ensino de física, em especial para o conteúdo aplicado na intervenção pedagógica, e também acreditamos que as pesquisas sobre o tema devem ser continuadas, como também acreditamos que a Sequência FEDATHI pavimenta um caminho para uma aprendizagem significativa, tendo em vista a preocupação com o conhecimento prévio dos alunos.

\section{Agradecimentos}

Agradecemos a Fundação Cearense de Apoio ao Desenvolvimento Científico e Tecnológico - FUNCAP, pelo apoio financeiro, e ao Mestrado Nacional Profissional em Ensino de Física (PROFIS/CAPES) coordenado pela sociedade Brasileira de Física.

\section{Referências}

[1] AUSUBEL, D.P., NOVAK, J.D. \& HANESIAN, H. Psicologia Educacional (Tradução de Educational Psychology, 1968). Rio de Janeiro, Interamericana, 1980.

[2] AUSUBEL, David. Aquisição e Retenção de Conhecimentos: Uma Perspectiva Cognitiva. Portugal: Plátano Edições Técnicas, traduzido por Lígia Teodoro, 2003.

[3] FOUREZ, G. Investigações em Ensino de Ciências, v. 8, pág. 109-123, 2003.

[4] OTTE, M. O formal, o social e o subjetivo: Uma introdução à Filosofia e a Didática da Matemática. São Paulo: UNESP Editora, 1991.

[5] HUETE, J.C.S.; BRAVO, J.A.F. O Ensino de Matemática: Fundamentos teóricos e bases psicopedagógicas. Porto Alegre: Artmed, 2006.

[6] POLYA, G. A arte de resolver problemas (Tradução de How to solve it, 1945). Rio de Janeiro, Interciência, 1995.

[7] BORGES NETO, H. B. (Coord.). Sequência Fedathi: Uma Proposta Pedagógica para o Ensino de Ciências e Matemática. Fortaleza, Edições UFC, 2013. 
[8] SOUZA, M.J.A. Aplicações da sequência Fedathi no ensino e aprendizagem da geometria mediado por tecnologias digitais. Fortaleza. f. 230 [ Tese (Doutorado) ]. Curso de Pós-Graduação em Educação. Faculdade de Educação, Universidade Federal do Ceará, 2010.

[9] LIBÂNEO, J. C. Adeus professor, adeus professora? Novas exigências educacionais e profissão docente. São Paulo: Cortez, 7 ed., 2003.

[10] ASSMANN, H. Ciência da Informação, v.29, n.2, Brasília. 2000.

[11] ASSMANN, H. Reencantar a Educação: Rumo a sociedade Aprendente. Petrópolis, RJ: Vozes, 1998, 4a ed. 2000.

[12] NOBRE, F. A. S.; SOUZA, A. I. E. S; SILVA, A. F. G. Sequência Fedathi. Fortaleza, Edições UFC, 2013.

[13] ARTIGUE, M. Ingénierie Didactique. In: BRUN, J. (Org.). Didactique des Mathématiques. Paris: Delachaux et Niestlé S.A, 1996.

[14] MINAYO, M. C. S. O desafio do conhecimento. Pesquisa qualitativa em saúde. São Paulo: Hucitec, 2007.

[15] THIOLLENT, M. Metodologia da Pesquisa-ação. São Paulo: Cortez. 2000.

[16] ERICKSON, F. Qualitative methods in research on teaching. In: Wittrock, M.C. (Ed.). Handbook of research on teaching. New York: Macmillan Publishing Co. pág. 119-161 1989.

[17] ERICKSON, F. Métodos cualitativos de investigación sobre la enseñanza. In: Wittrock, M.C. (Comp.). La investigación en la enseñanza, II. Barcelona, Paidós. pág. 195-301, 1986.

[18] MEDEIROS, A. MEDEIROS, C. F. Revista Brasileira de Ensino de Física. Porto Alegre/RS, v. 24, n. 2, p. 79, 2002. 